\title{
Research Paper: Effectiveness of Group Play Therapy on the Communication of 5-8 Years Old Children With High Functioning Autism
}

\author{
Fateme Shah Rafati ${ }^{1},{ }^{*}$ Masoume Pourmohamadreza-Tajrishi², Ebrahim Pishyareh ${ }^{3}$, Houshang Mirzaei ${ }^{3}$, Akbar Biglarian ${ }^{4}$
}

1. Department of Psychology and Exceptional Children Education, University of Social Welfare and Rehabilitation Sciences, Tehran, Iran.

2. Pediatric Neurorehabilitation Research Center, Department of Psychology and Exceptional Children Education, University of Social Welfare and Rehabilitation Sciences, Tehran, Iran.

3. Department of Occupational Therapy, University of Social Welfare and Rehabilitation Sciences, Tehran, Iran.

4. Department of Biostatistics, University of Social Welfare and Rehabilitation Sciences, Tehran, Iran.

Citation: Shah Rafati F, Pourmohamadreza-Tajrishi M, Pishyareh E, Mirzaei H, Biglarian A. [Effectiveness of Group Play Therapy on the Communication of 5-8 Year Old Children With High Functioning Autism (Persian)]. Journal of Rehabilitation. 2016; 17(3):200-211. http://dx.doi. org $/ 10.21859 /$ jrehab-1703200

: http://dx.doi.org/10.21859/jrehab-1703200

Received: 27 Feb. 2016

Accepted: 21 May 2016

Keywords:

High functioning

autism, Communi-

cation, Group play

therapy

\begin{abstract}
A B STRACT
Objective Communication deficiency is one of the diagnostic criteria for autism, which leads to difficulty in learning speech and linguistic skills. Nowadays, it is common to use play therapy for supporting children with autism. Play therapy is an active approach that helps a child to reveal his conscious and unconscious feelings through playing. The present study aimed to determine the effectiveness of group play therapy on the communication skills of children with high functioning autism.

Materials \& Methods The present research was an experimental study, including a pretest and posttest design with a control group. Twelve 5-8 years old boys with high functioning autism were selected purposively from the Autism Charity Foundation in Tehran in 2013. All subjects were included according to get a diagnose of high functioning autism, literacy of parents to complete the questionnaire, lack of sensory disorders such as visual or auditory disorders, lack of physical or motor disorders such as cerebral palsy, not attending to the same play therapy intervention program simultaneously. All subjects were assigned randomly to the experimental and control groups ( 6 children in each group). The experimental group participated in 20 sessions (three times a week; 45 to 60 minutes for each session) and received group play therapy along with the routine program (mental and physical occupational therapy, and speech therapy). However, the control group received only the routine program. The communication skills of all the children were evaluated using the Gilliam Autism Rating Scale (GARS) before, at $20^{\text {th }}$ session, and 2 months after the intervention. The collected data from two situations (pre-test, post-test) were analyzed by analysis of covariance. Repeated measure test was used to determine the lasting effect of group play therapy on the communication of boys after two months follow-up. Results The findings of the analysis of covariance showed that the group play therapy significantly influenced the communication of male children with high functioning autism. In addition, it was found that the effects of the group play therapy lasted significantly on the communication skills of the children even at two months follow-up $(P<0.001)$.

Conclusion It is concluded that the group play therapy can help the children to understand and communicate well. This therapy can be used as a complementary training and therapeutic method for children with high functioning autism to help improve their communication deficiencies.
\end{abstract}

* Corresponding Author:

Masoume Pourmohamadreza-Tajrishi, PhD

Address: Pediatric Neurorehabilitation Research Center, Department of Psychology and Exceptional Children Education, University of Social Welfare and Rehabilitation Sciences, Koodakyar Ave., Daneshjoo Blvd., Evin, Tehran, Iran.

Tel: +98 (21) 22180042

E-Mail: mpmrtajrishi@gmail.com 


\title{
اثربخشى بازى درمانى تروهى بر ارتباط كودكان ه تا مسال مبتلا به اختلال اتيسم با عملكرد بالا
}

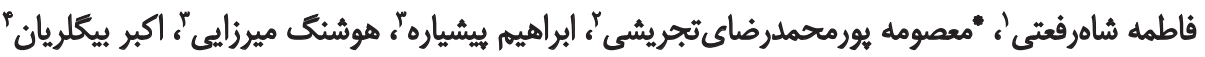

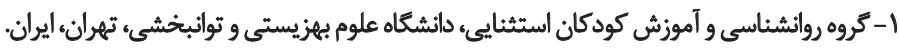

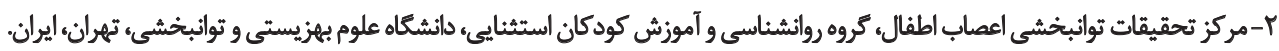

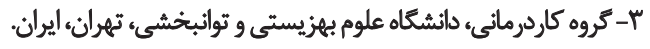 \\ F - كروه آمار زيستى، دانشكاه علوم بهزيستى و توانبخشى، تهران، ايران.
}

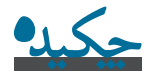

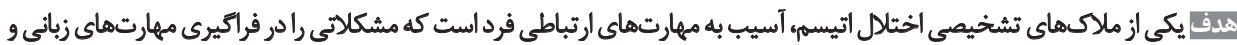

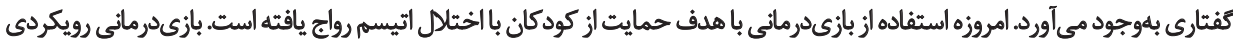

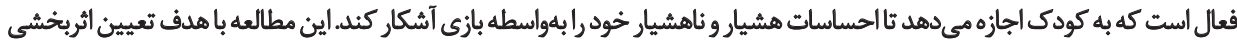

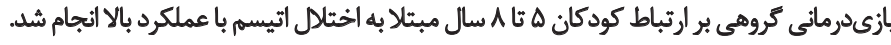

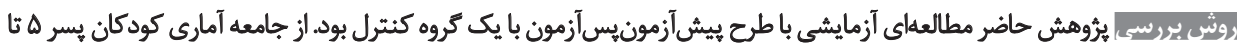

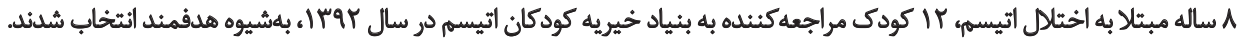

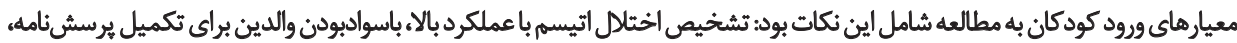

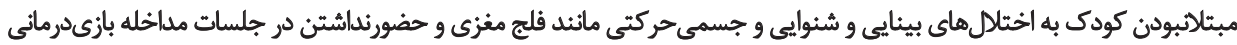

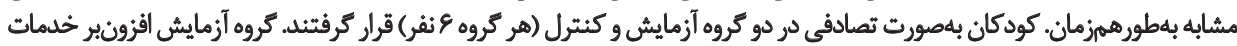

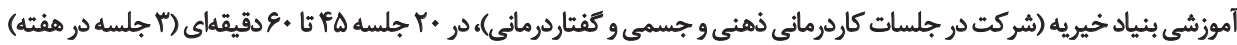

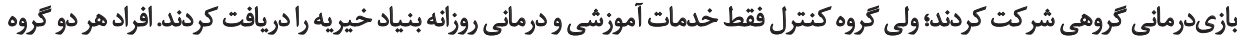

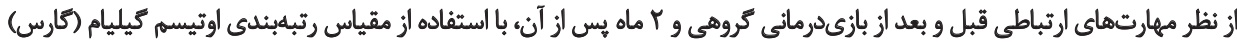

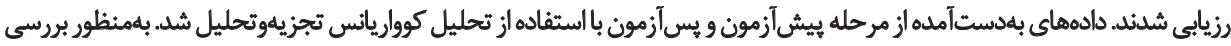

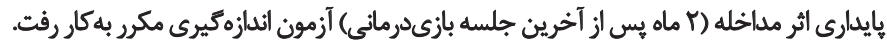

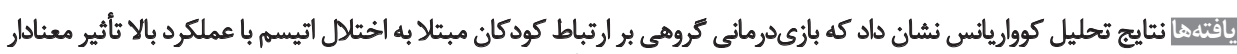

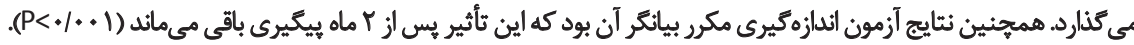

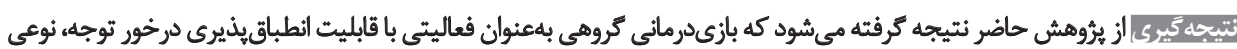

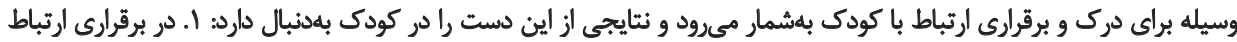

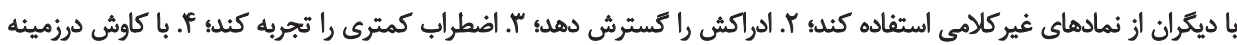

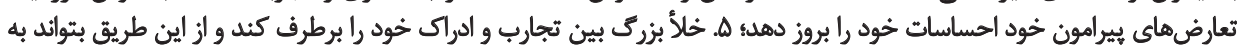

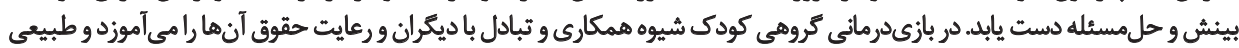

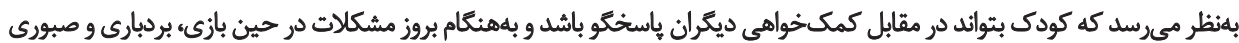

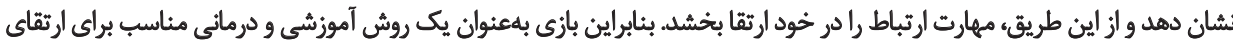

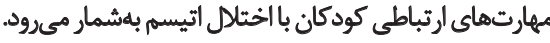

تاريخ دريافت: A+ اسفئد

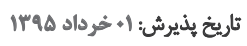

كليدوأزها:

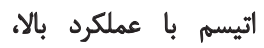

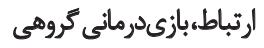

ㄷ…......

" نويسناه مسئول:

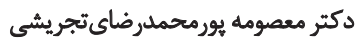

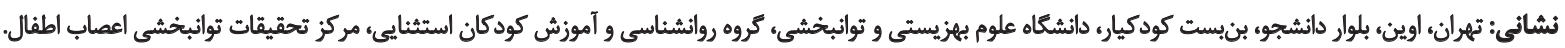
+

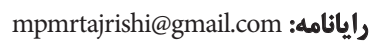


درمانى از اولويت برخوردار است [ 1 ، 11]]. درحال حاضر رايجترين

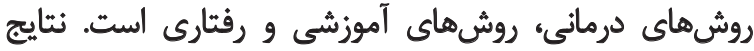

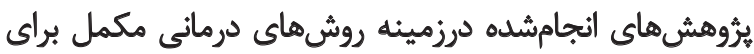

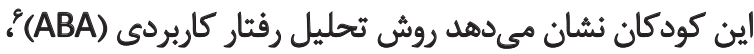

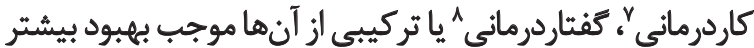

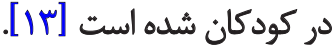

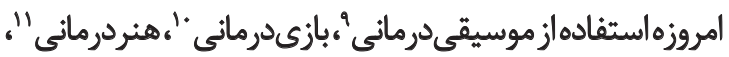

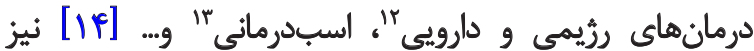

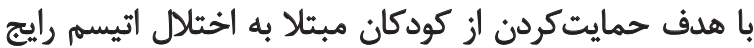

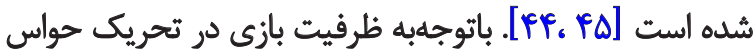

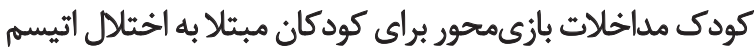

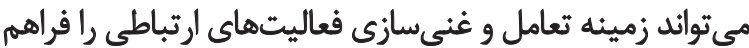

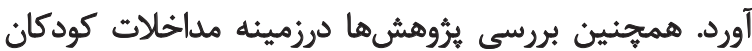

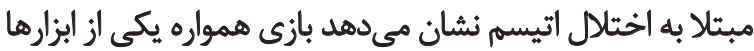

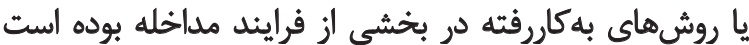

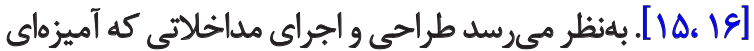

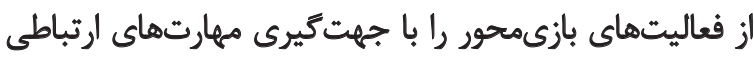

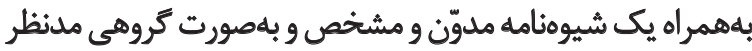
قرار مى دهد، از ديدكاه نظرى نيز يك اولويت مئن تخصصى محسوب

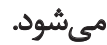

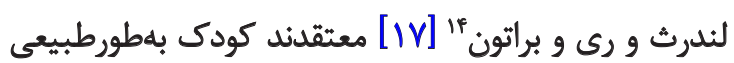

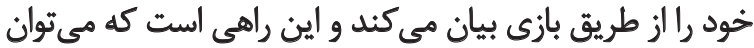

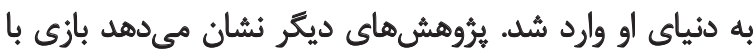

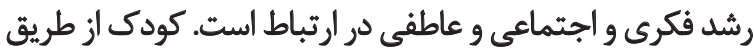

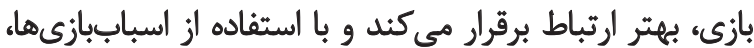

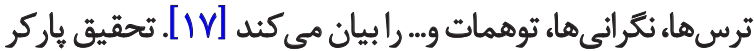

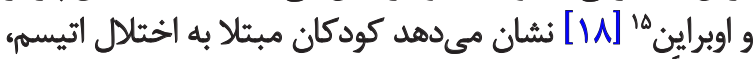

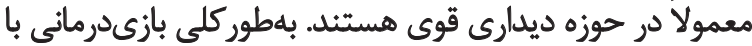

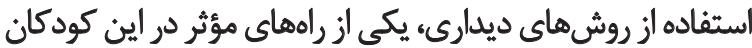

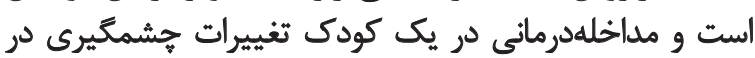

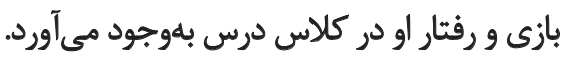

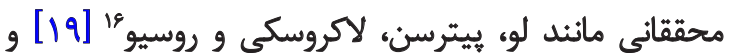

6. Applied Behavior Analysis (ABA)

7. Occupational therapy

8. Speech therapy

9. Music therapy

10. Play therapy

11. Art therapy

12. Dietary and medication treatments

13. Hippo therapy

14. Landreth, Ray and Bratton

15. Parker and O'Brien

16. Lu, Petersen, Lacroix and Rousseau
مقدمه

اتيسم 'نوعى اختلال تحولى فراكيرج است كه بيشتر بلعنوان

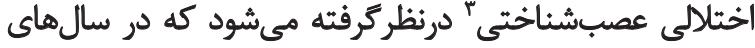

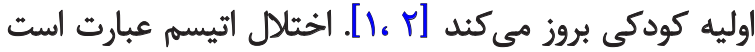

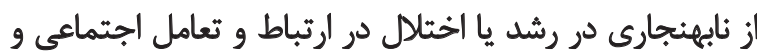

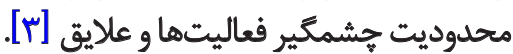

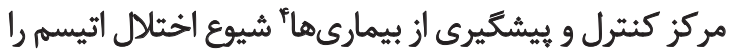

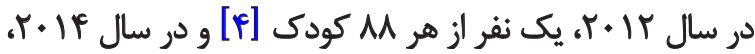

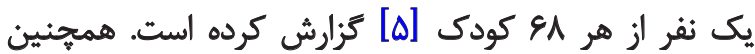

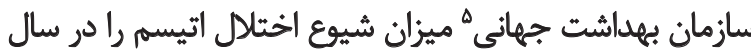

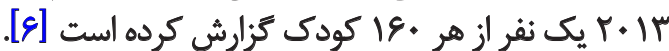

باتوجهبه هسته مركزى اختلال، كودكان مبتلا به اختلال

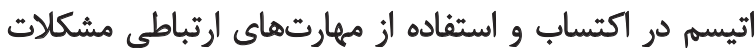

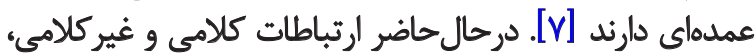

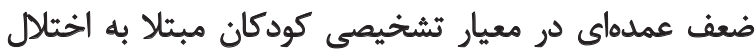

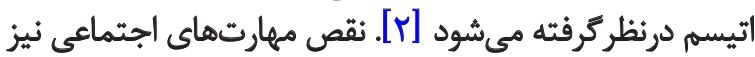

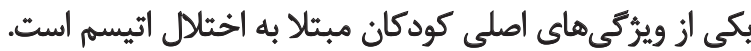

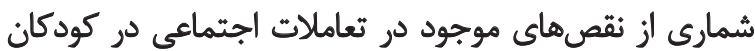

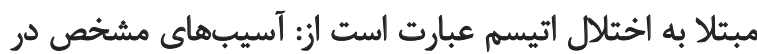

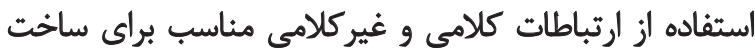

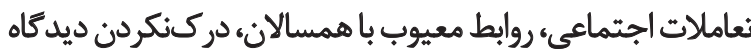

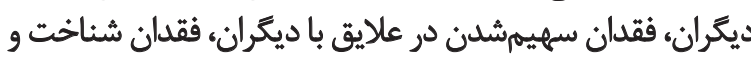

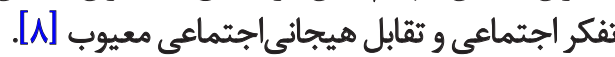
نقص در مهارتهاي بازى كردن بلويثره كاستى در بازى نمادين

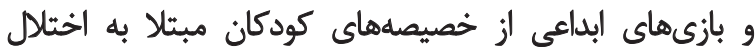

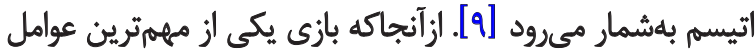

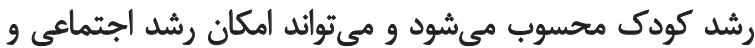

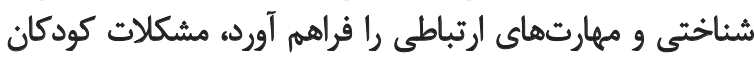

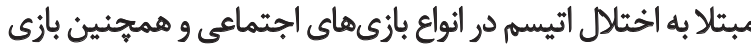

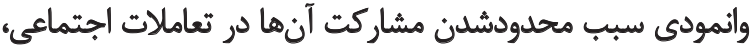

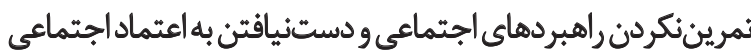
و مهارتهاى ضرورى براى استقلال اجتماعى مى اجشود [ـ [1].

اكرجه در كودكان عادى فرايند درى و رشد ميهارتهاي ارتباط

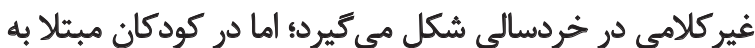

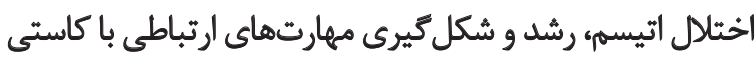

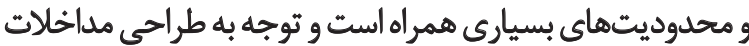

1. Autism

2. Pervasive Developmental Disorder (PDD)

3. Neurological

4. Centers for Disease Control and Prevention (CDC)

5. World Health Organization (WHO) 


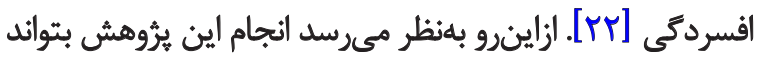

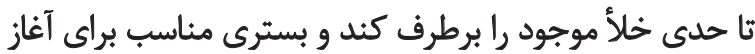

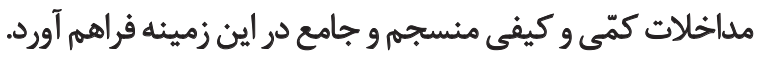

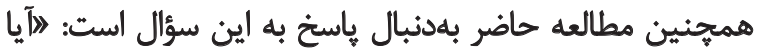

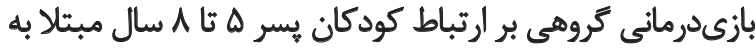
اختلال اتيسم با عملكرد بالا مؤثر است؟ كرونه

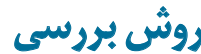

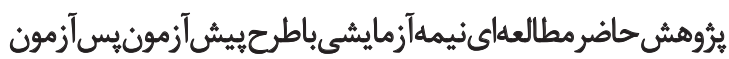

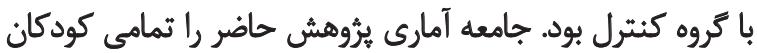

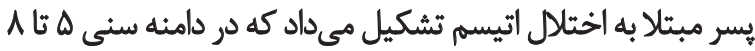

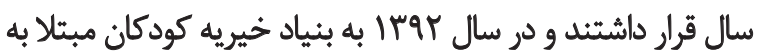

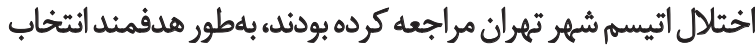

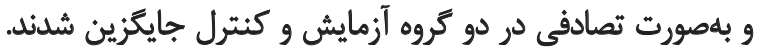

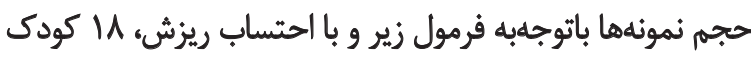

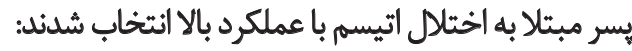

\section{$N=2 \delta^{2}(z B-z \alpha)^{2} /(d) 2=2 \times 7^{2}(0.84+1.96)^{2} / 8^{2}=12$}

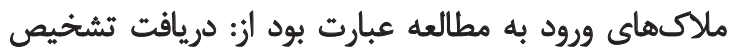

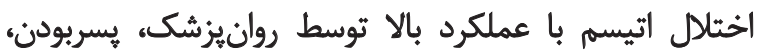

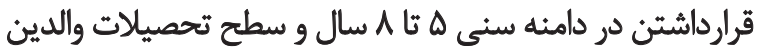

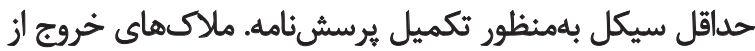

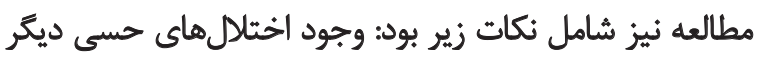

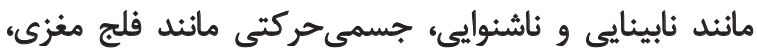

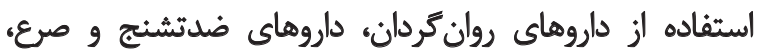

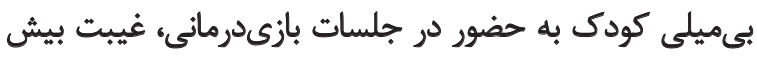

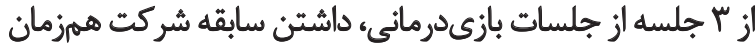
در مداخلههاى مشابه با مداخله برؤوهش حاضي، داضر.

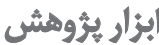

بهمنظور جمع آورى دادهها از مقياس رتبهبيندى اتيسم كيليام

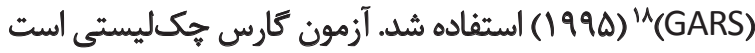

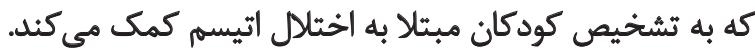

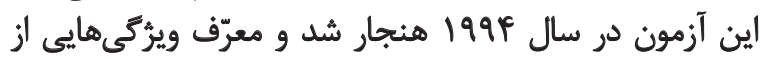

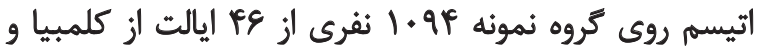

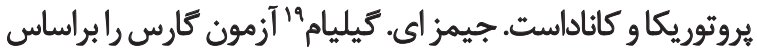

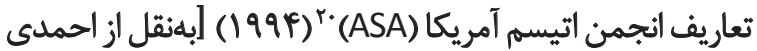

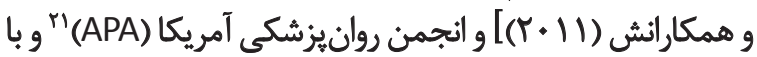
اتكا بر نسخه جهارم راهنماى تشخيصى و آمارى اختلالات آنات روانى

18. Gilliam Autism Rating Scale (GARS)

19. Gilliam

20. Autism Society of America (ASA)

21. American Psychiatry Association (APA)
ديويس "r.r] مداخلات توانبخشى و درمانى را در كودكان

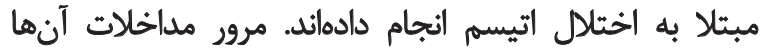

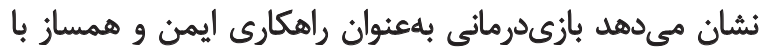

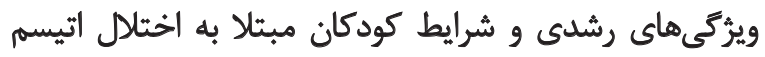

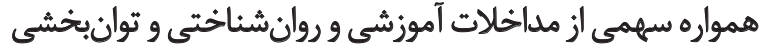

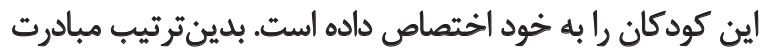

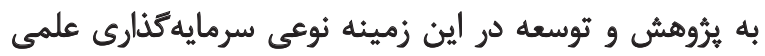

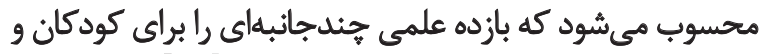

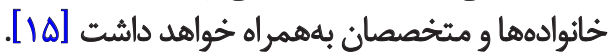

بازىدرمانى كروهى إيوند طبيعى دو شيوه مداخلاتى مؤثر

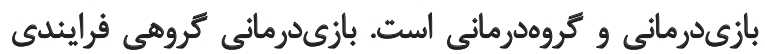

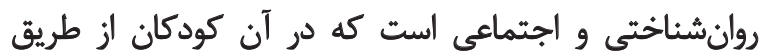

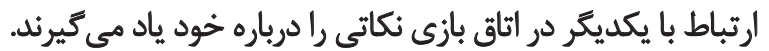

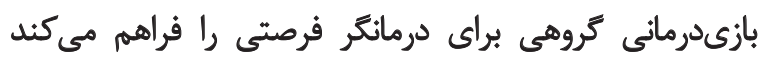

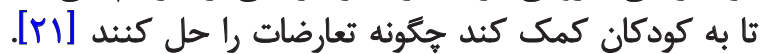

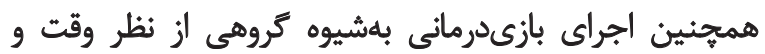

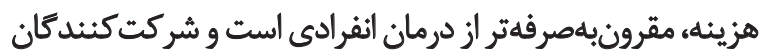

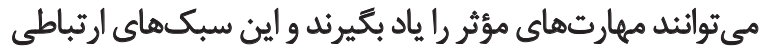

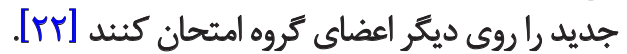

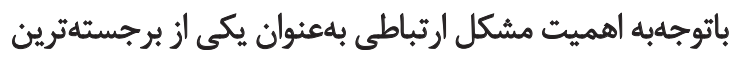

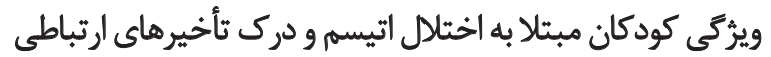

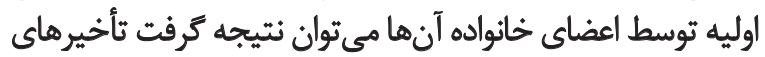

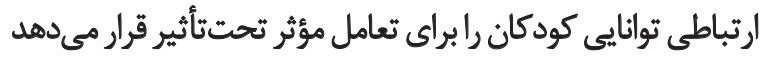

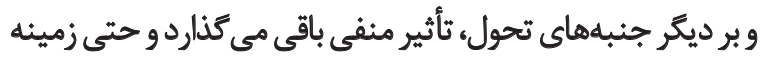

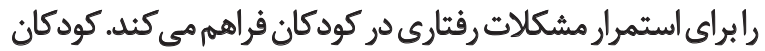

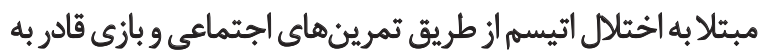

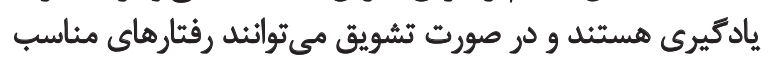

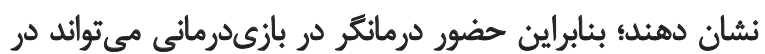

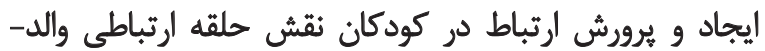

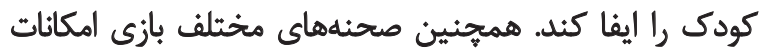

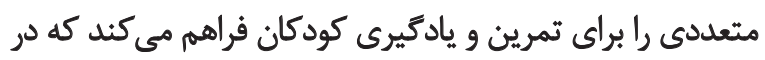

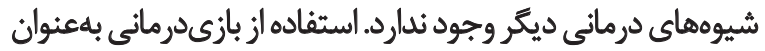

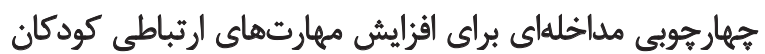

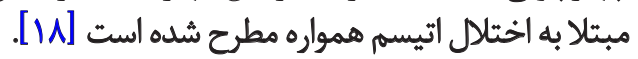
تاجايى كه بررسى هاى ئروهشكران نشان ميدهدان تاكنون

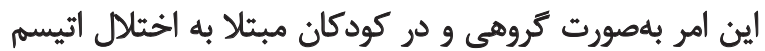

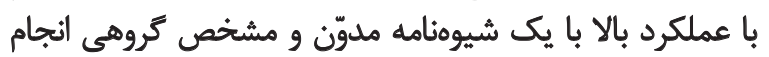

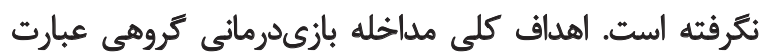

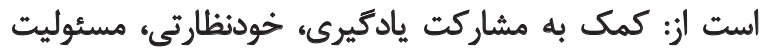

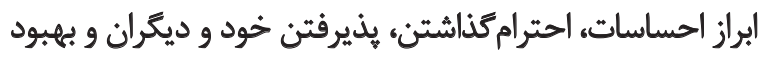

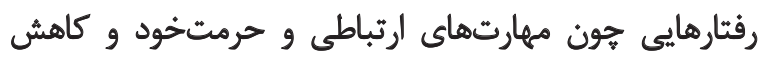


شديد رفتارى ديكر متمايز كند؛

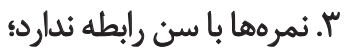

Ff. اشخاص با شخصيتهاى مختلف نمرههاى متفاوتى در

$$
\text { كارس از خود نشان مي دهند. }
$$

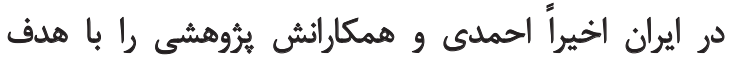

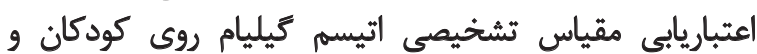
نوجوانان مبتلا به اختلال اتيسم در استان اصفهان انجام انيام دادهاند.

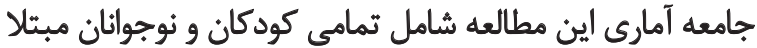

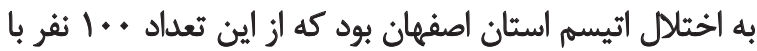

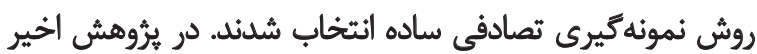

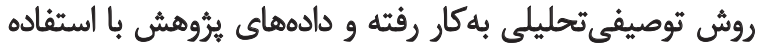
از مقياس كارس و مقياس رتبلهبندى اتيسم كودكى (CARS)

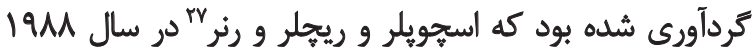

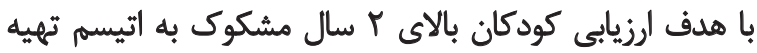

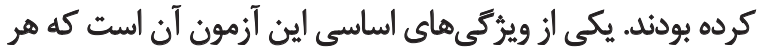

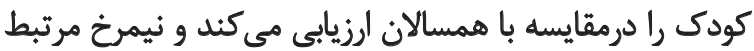

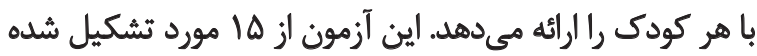

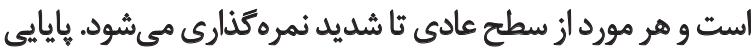

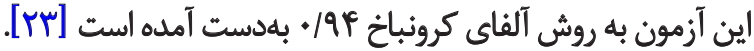

متخصصان و كارشناسان مركز اتيسم اصفهان روايى صورى

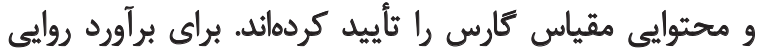

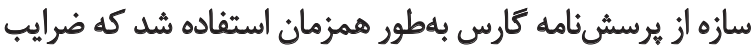

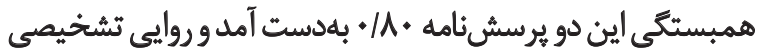

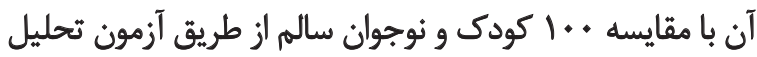

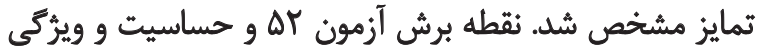

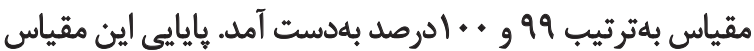

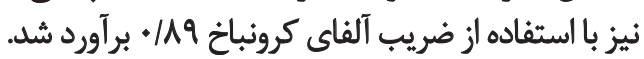
يافتهها نشان داد كه مقياس تشخيصى اتيسم تيليام ابزارى

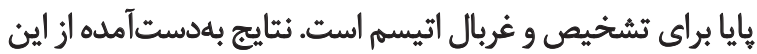

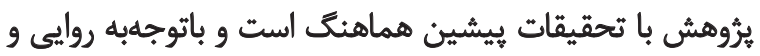

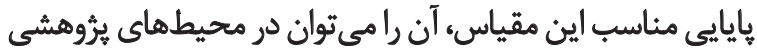

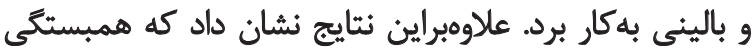

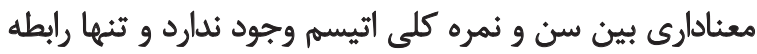

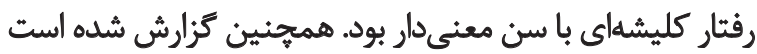

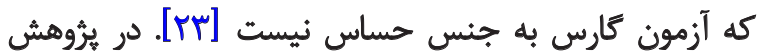

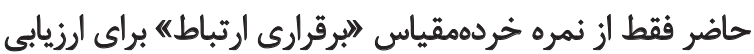

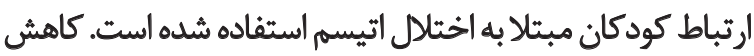
اين نمره بهبود و ويشرفت ارتباط كودى رانشان رانشان ميدهد.

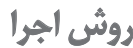

26. Childhood Autism Rating Scale (CARS)

27. Schopler, Reichler \& Renner
"TSSM-IV)

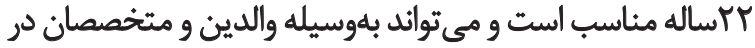

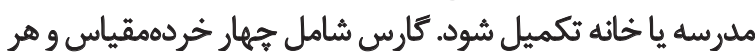

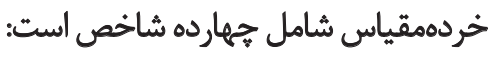
ا. رفتارهاي كليشهاي كه موارد رفتارهاي كليشهاي و اختلالات

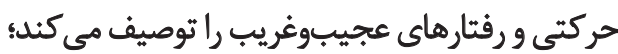
ك. خردهمقياس دوم درزمينه برقرارى ارتباط است و رفتتارهاى

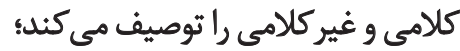

"ا. تعاملات اجتماعى كه موضوعاتى را الرزيابى مي كند كه قادر است بلطور مناسب رويدادها و رفتارهاي افراد رادي را شرح دهدئ f. اختلالات رشدى كه درباره سير رشد كودكى افراد سؤال

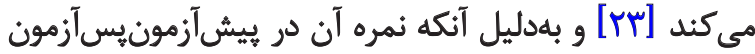

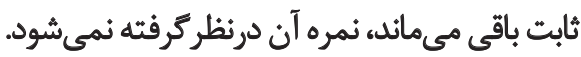

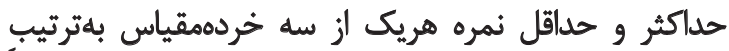

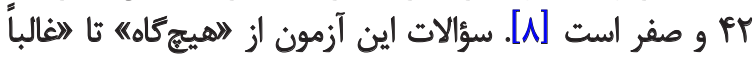

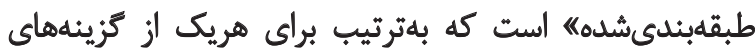

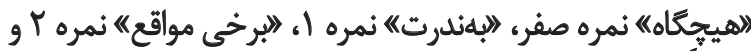

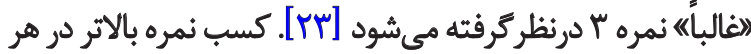

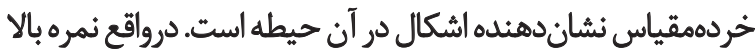

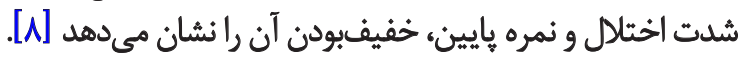

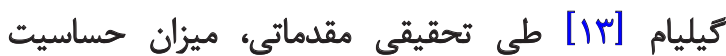

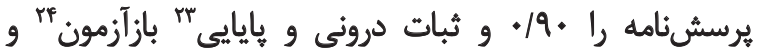

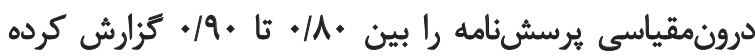

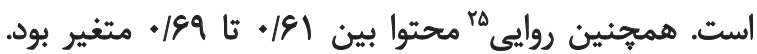

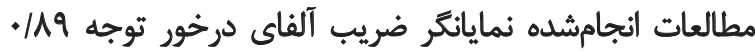

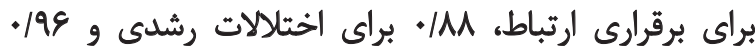

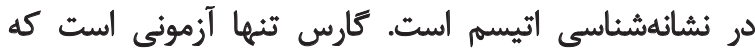

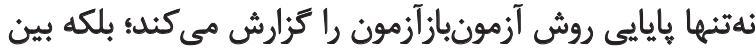

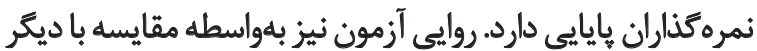

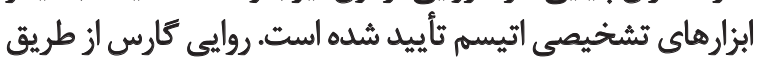

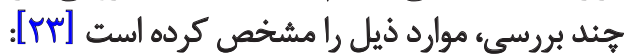

ا. سؤالهاي خردهمقياسها معرّف ويرَّى هاى كودكان مبتلا به اختّلال اتيسم استك

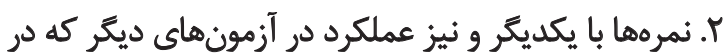

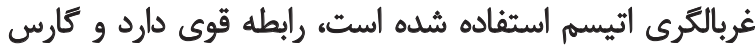

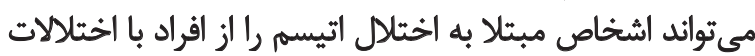

22. Diagnostic and Statistical Manual of Mental Disorders (DSM-IV) 23. Reliability

24. Test-retest

25. Validity 
براساس نظريههاى رشد اجتماعى و تقسيمبندى بازى از ديدكاه

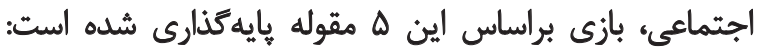

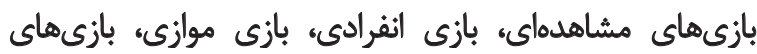

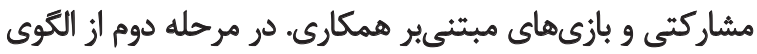

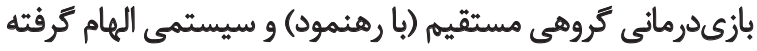

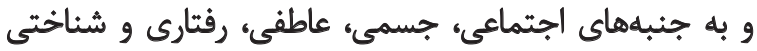

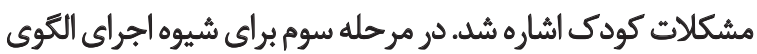

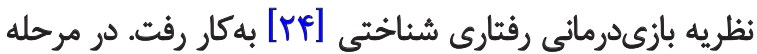

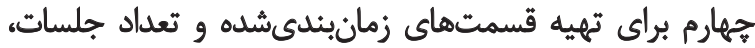

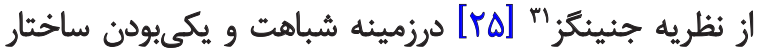

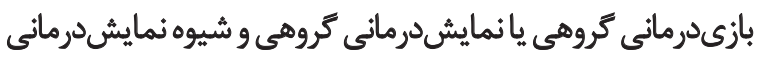

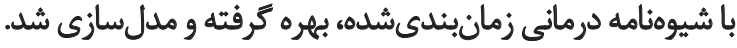

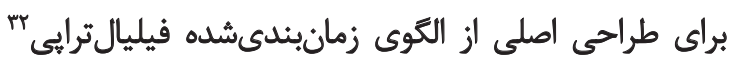

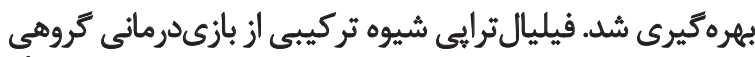

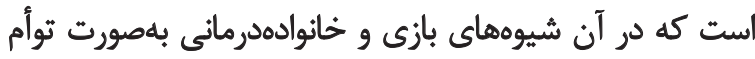

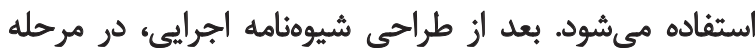

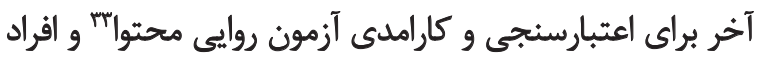

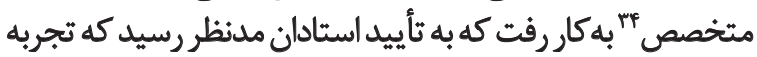

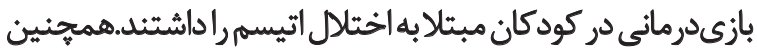

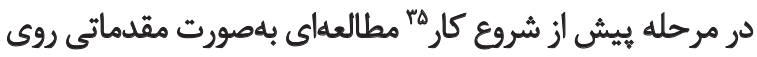

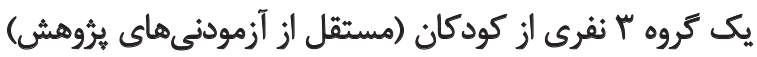

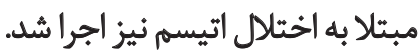

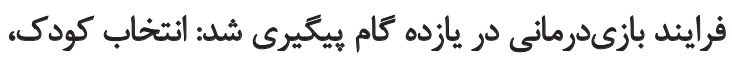

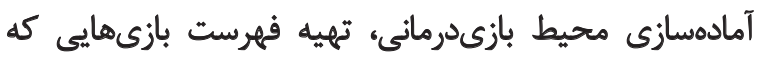

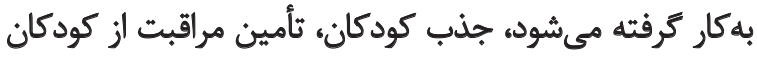

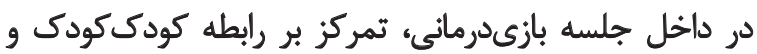

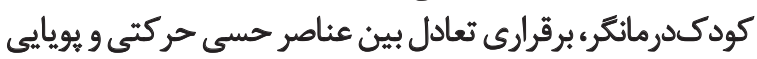

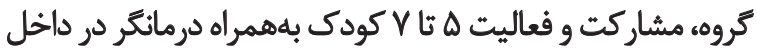

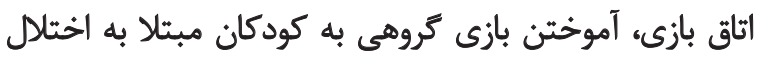

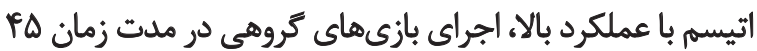

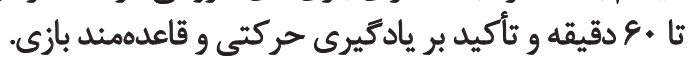

ساختار جلسات درمانى در يروهش حاضر بلشرح زير بود:

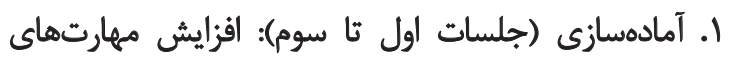

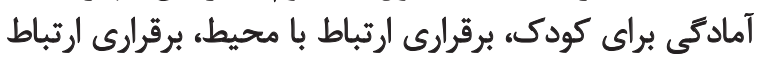

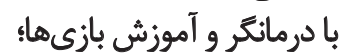

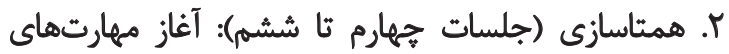

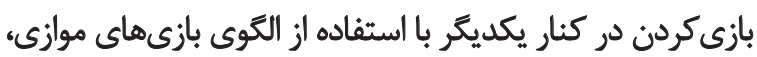

31. Jennings

32. Filial therapy

33. Content validity

34. Expert

35. Curriculum vita

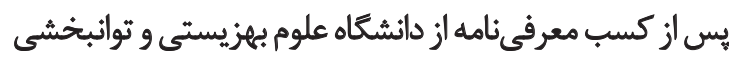

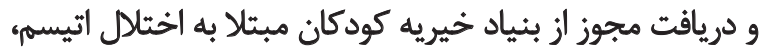

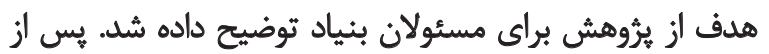

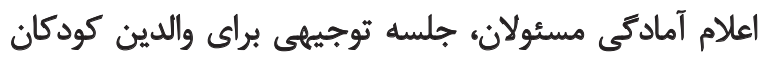

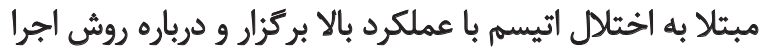

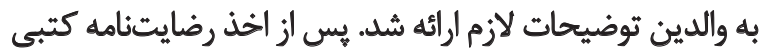

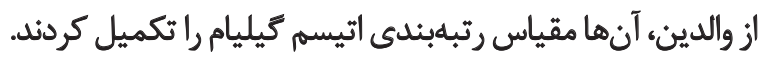

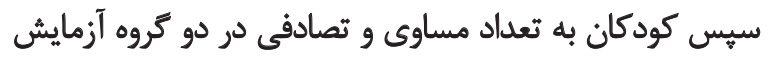

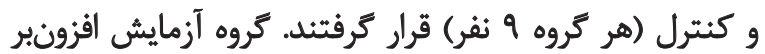

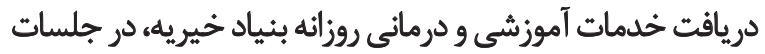

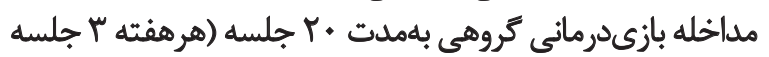

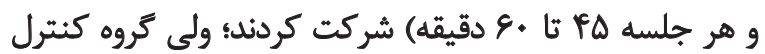

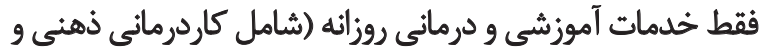
جسمى و كفتاردرمانى) را ادريافت كردند

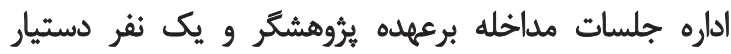

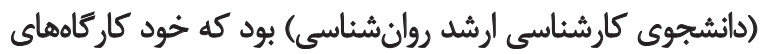

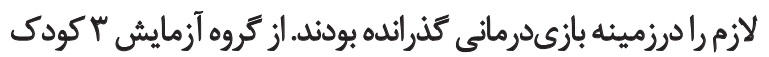

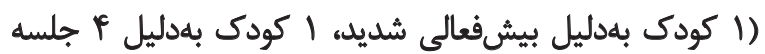

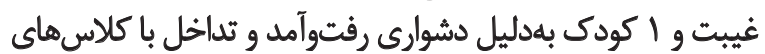

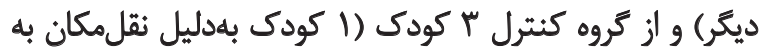

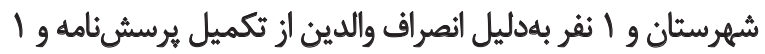

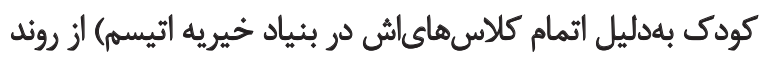

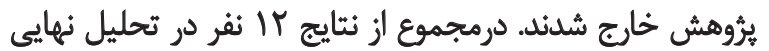

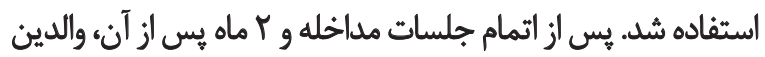
دوباره مقياس رتبهبندى اتيسم كيليام را تكميل كردند.

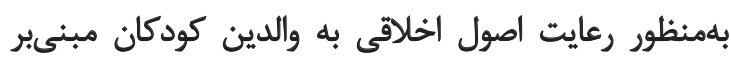

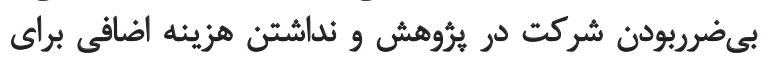

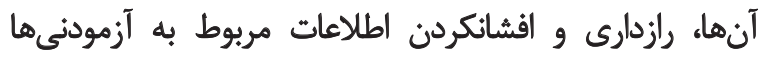

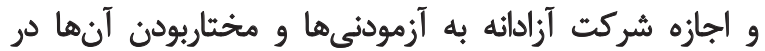

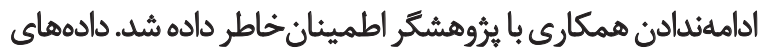

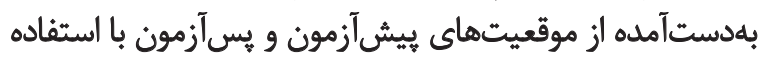

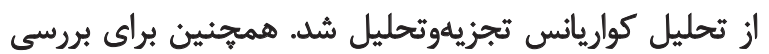

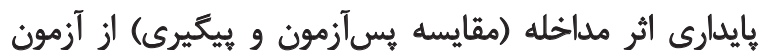

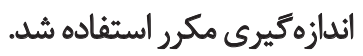

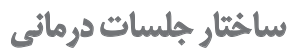

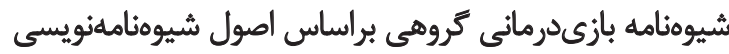

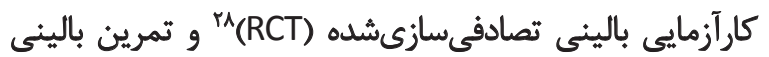

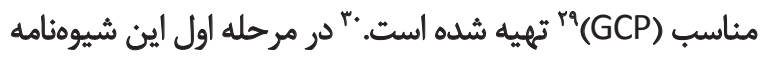

28. Randomized Clinical Trail (RCT)

29. Good Clinical Practice (GCP)

ك.r. براى اطلاعات بيشتر به RCT.IR يا مركز كارآزمايى بالينى دانشعاه تهران مراجعه 
آزمون شاييرو ويلك و لوين (جداول r ب س) شرط طبيعىبودن توزيع

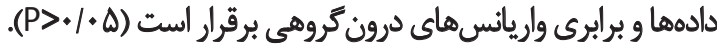

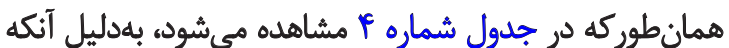

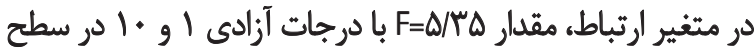

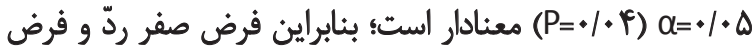

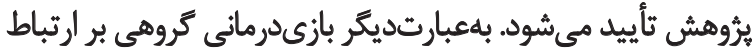

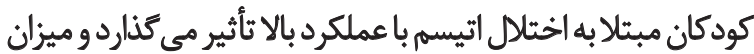

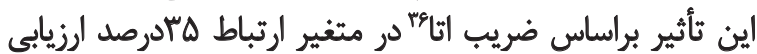

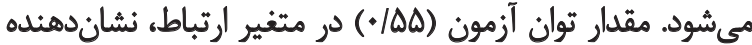

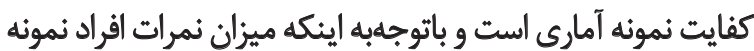

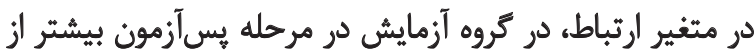

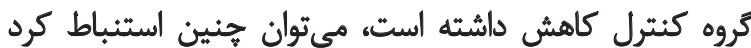

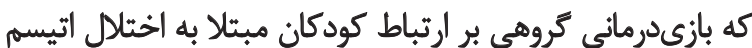

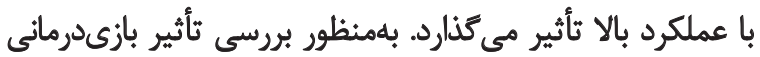

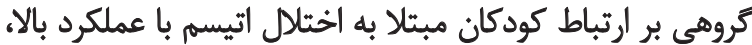
يس از كذشت ب باه از تحليل اندازههاي مكرر استفاده شده است. همانطوركه در جدول شماره ه ملاحظه مى ارشود، در متغير

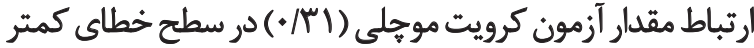

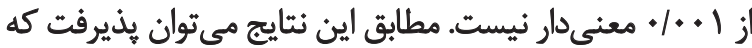

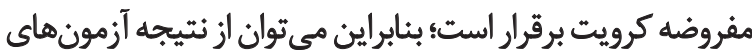

36. Eta quotient

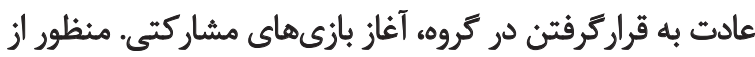

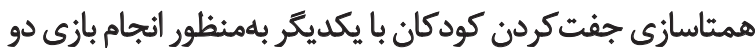
نفره الست؛ r. همكارى (جلسات هفتم تا نوزدهم): انجام بازىهاى

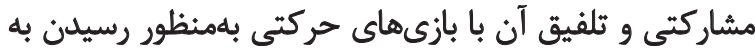
الكوى بازىهاى مفهومى، رقابت، همكارى و مشاركت؛ f. جمعبندى (جلسه بيستم): بازى ادرمانى باكودى و مشاهده

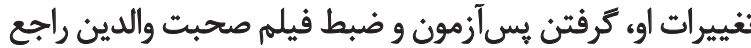

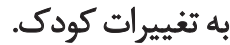

Ladię)

آزمودنىها شامل با ڤيسر با دامنه سنى ه تا 1 سال بودئد.

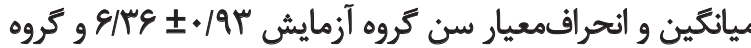

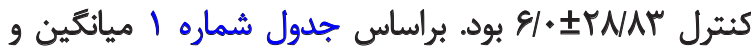

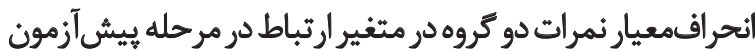

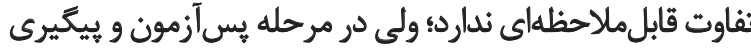

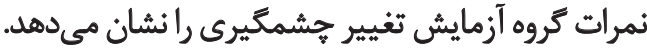

بهمنظور آزمون اثربخشى بازىدرمانى تروهى بر ارتباط كودكان

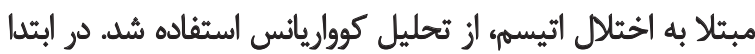

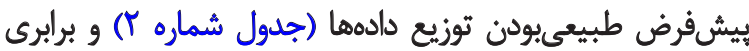

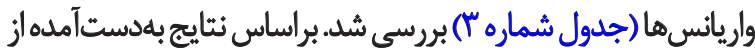

جدول ا. شاخصهاى ثوصيفى برقرارى ارتباط در بيش آزمون و بسأزمون و بيكيرى دو كروه آزمايش وكنترل.

\begin{tabular}{|c|c|c|c|c|c|c|c|}
\hline \multicolumn{2}{|c|}{ ييكيرى } & \multicolumn{2}{|c|}{ هيسآزمون } & \multicolumn{2}{|c|}{ بيش آزمون } & \multirow{2}{*}{ كروه } & \multirow{2}{*}{ مثغير } \\
\hline انحرافمعيار & مياتعين & انحرافمعيار & مياتكين & انحرافمعيار & مياتكين & & \\
\hline$\Delta / A \mid$ & V/Ar & $t / T$ & $r / \Delta+$ & Nor & $1 r / \Delta$. & آزمايش & \\
\hline$s / 4$ & IVIV & $V / \Delta F$ & ir & $v / / 9$ & $1 \mathrm{~W} / \mathrm{r}$ & كتترل & \\
\hline
\end{tabular}

توانبخننى

جدول ז. بررسى طبيعىبودن توزيع دادها با استفاده از آزمون شائيرو-ويلك در متغير ارتباط دو كروه آزمايش و كنترل.

\begin{tabular}{|c|c|c|c|c|}
\hline \multicolumn{3}{|c|}{ أزمون شاييرو-ويلك } & \multirow{2}{*}{ كروه } & \multirow{2}{*}{ متغير } \\
\hline سطح معنادارى & درجه آزادى & مقدار & & \\
\hline$+1+1$ & 8 & - MAT & أزّمايش & 4 \\
\hline.$/ . Y$ & 8 & MV & كثترل & الربعاط \\
\hline
\end{tabular}

توانبخنىى

جدول با. نتايج آزمون لوين براى بررسى برابرى واريائهاى درون كروهى بهتفكيك كروه آزمايش و كنترل.

\begin{tabular}{|c|c|c|c|c|}
\hline سطح معناداري & $d f^{r}$ & df' & $\mathbf{F}$ & هتغير \\
\hline.$/ 4 \varphi$ & 1. & 1 &.$/ 99$ & ارتباط \\
\hline
\end{tabular}


جدول f. نتايج تحليل كوواريانس براى مقايسه ميانكين نمرات ارتباط در كروههاى مطالعهشده با كثترل اثر بيش آزمون.

\begin{tabular}{|c|c|c|c|c|c|c|c|}
\hline توان أزمون & ضريب اتا & سطح معنادارى & ملاك آزمون & درجه آزادى & مجموع مربعات & متغيرها & \\
\hline.$/ 99$ & $\cdot M T$ & $<+1++1$ & $r \Delta / \wedge q$ & 1 & NIS/ND & ييشأزمون & \\
\hline \multirow[t]{3}{*}{.$/ \Delta \Delta$} &.$/ 2 \Delta$ & $\%$ & $\Delta / \Gamma \Delta$ & 1 & ISNVA & Sروه & Wh. \\
\hline & & & & 1. & $\Gamma \Delta / \Delta$. & خطا & \\
\hline & & & & Ir & $15 \% / 9 q$ & كل & \\
\hline
\end{tabular}

توانبخننى

جدول هـ نتايج آزمون كرويت موجلى اثر بين آزمودنى در موقعيث بيكيرى.

\begin{tabular}{|c|c|c|c|c|c|}
\hline ترينهاوس-يسيسر & سطح معنى دارى & درجه أزادى & $x^{r}$ & كرويت موحلى & اثر بين آزمودثى \\
\hline .109 & Tr/ & $r$ & $r / A r$ & I & ارتباط \\
\hline
\end{tabular}

توانبخنىى

جدول و. ئتايج تحليل اندازهماى مكرر در بررسى بايدارى تأثير بازىدرمانى گروهى بر ارتباط كودكان با اختلال اتيسم با عملكرد بالا.

\begin{tabular}{|c|c|c|c|c|c|c|}
\hline سطح معنادارى & ملاك آزمون & درجات آزادى & مجموع مجذورات & منيع تغييرات & & \\
\hline.$/ .1$ & $\Delta / A r$ & r & $w / N$ & كرويت فرضشده & \multirow{2}{*}{ كروه } & \multirow{2}{*}{ ارتباط } \\
\hline$\% r$ & $\Delta / A r$ & $1 / M$ & $W / N$ & كرينهاوس-كيسر & & \\
\hline
\end{tabular}

توانبخننى

جدول ل. نتايج آزمون تعقيبى بونفرونى در مثايسه اختلاف ميانكين.

\begin{tabular}{|c|c|c|c|c|}
\hline سطح معنادارى & انحرافمعيار & اختثلاف ميانكين (J-1) & I & J \\
\hline.$/ 1$ & $\varphi / \mu f$ & $T T / / Y$ & يسآزمون & \multirow{2}{*}{ ييش آزمون } \\
\hline $.1 .0 \%$ & $r / Y \Lambda$ & $\bullet \mathbb{M}$ & ييكيرى & \\
\hline
\end{tabular}

توانبخننى

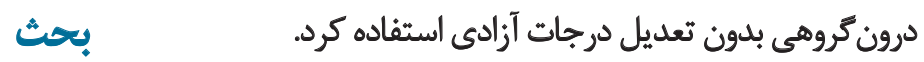

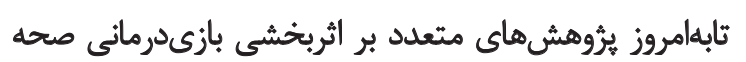

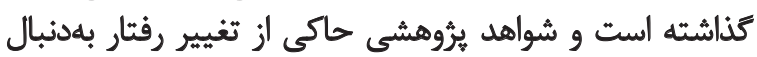

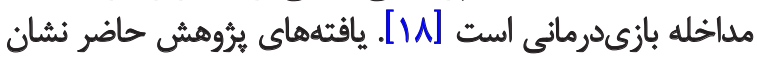

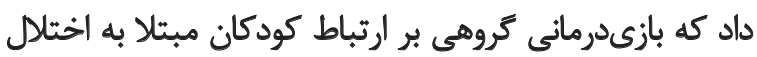

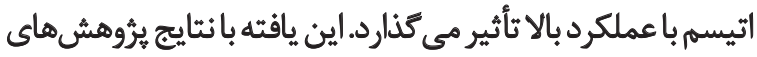

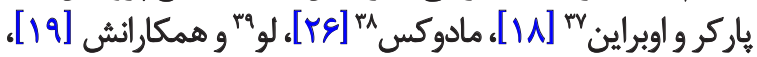

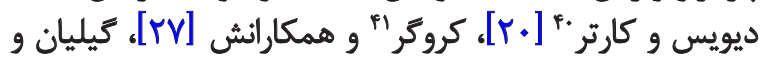

37. Parker and O'Brien

38. Maddox

39. Lu

40. Davis and Carter

41. Kroeger

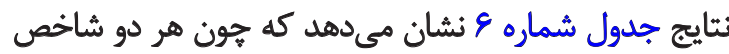

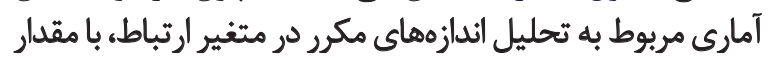
F=ه/Ar

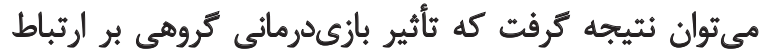

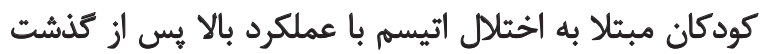

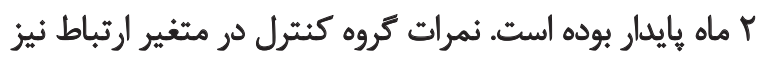

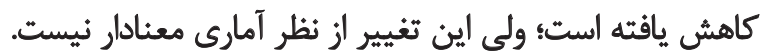

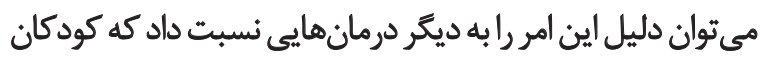

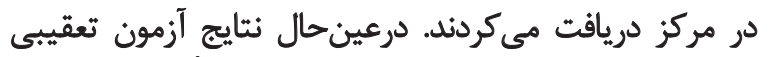

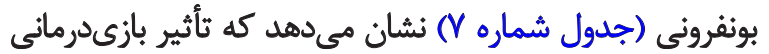

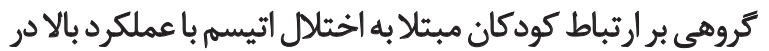

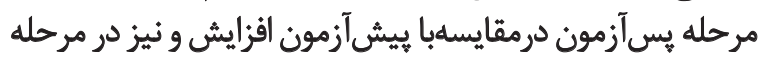
بيكيرى نيز اين افزايش تداوم داشته است. 
با همسالان تأثير بكذارد. در محيطهاى تلفيقى كه كودكان مبتلا

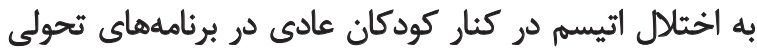

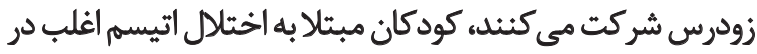

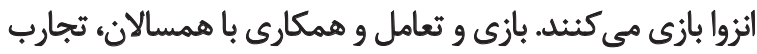

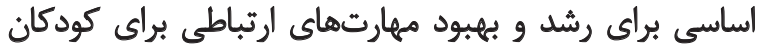

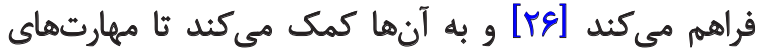

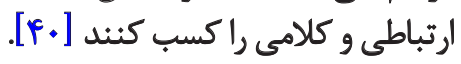

اختلالهاى بيان و احساسها و هيجانها در كودكان مبتلا

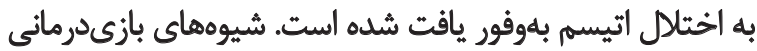

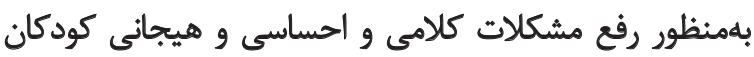

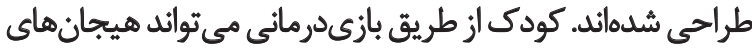

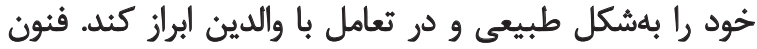

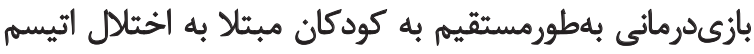

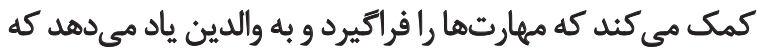

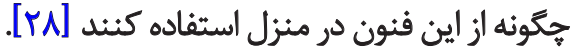

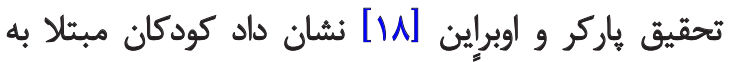

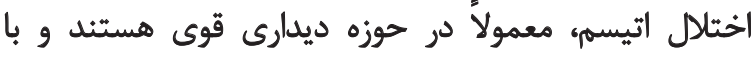

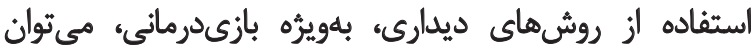

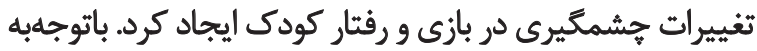

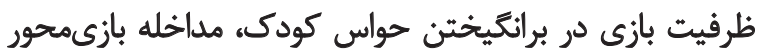

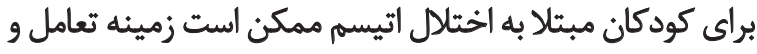
غنى سازى فعاليتهاى ارتباطى را فراهم آورد.

در خلال بازيدرمائى فرصتهايى فراهم مي شيود كه كودى در تعامل با افراد و وسايل بازي، فعاليتهائهائ حسى فري، حركتئي،

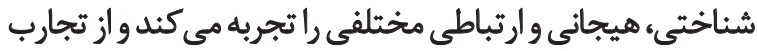

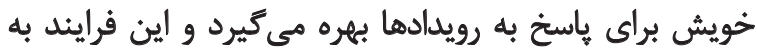

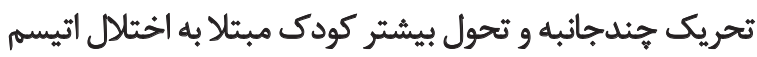

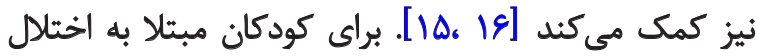

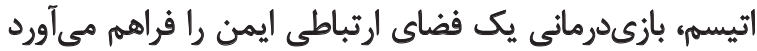

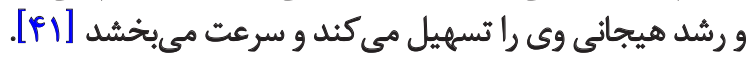

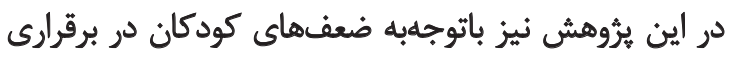

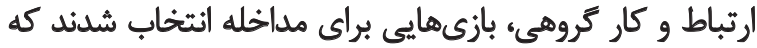

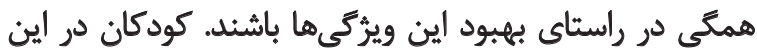

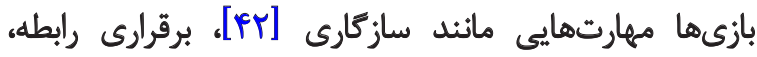

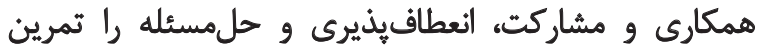

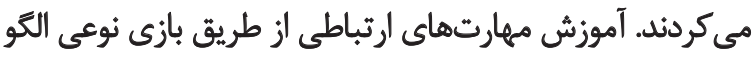

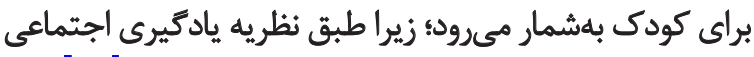

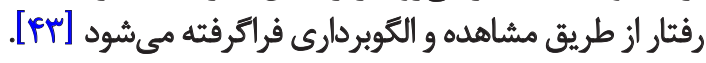

اثربخشى بازىدرمانى كروهى بر ارتباط در كودكان مبتلا به

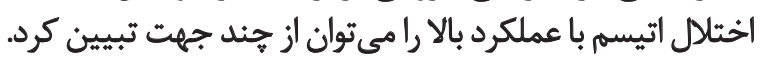

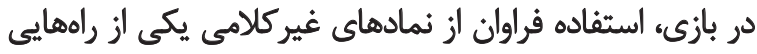

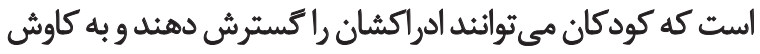

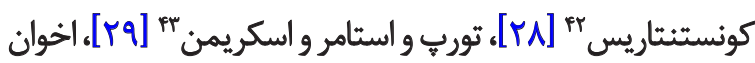

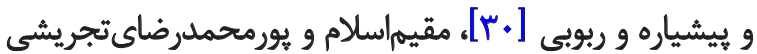

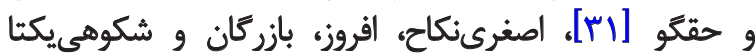

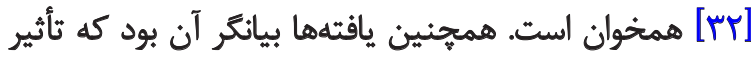

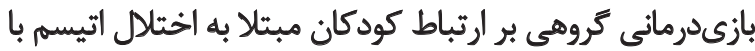

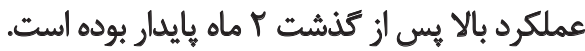

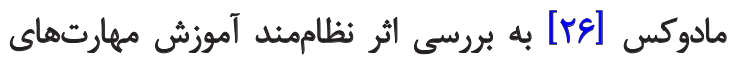

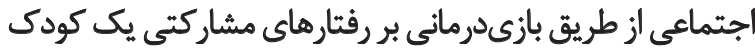

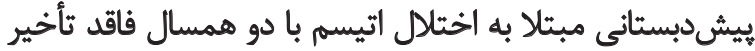

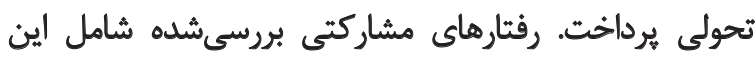

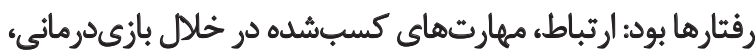

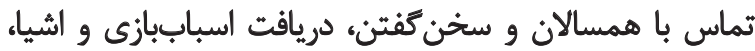

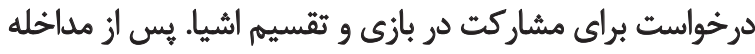

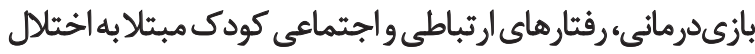

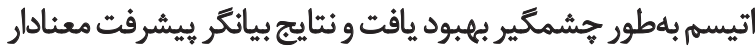

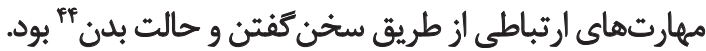

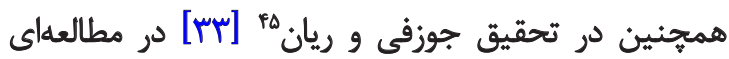

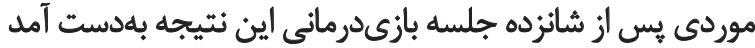

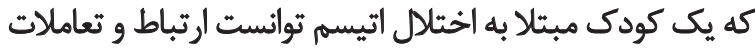

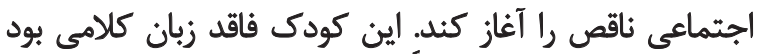

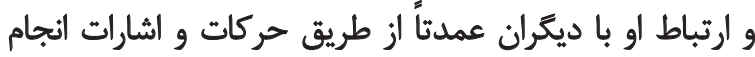

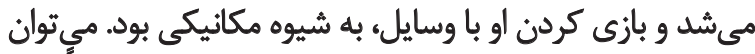

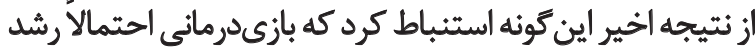

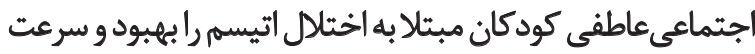

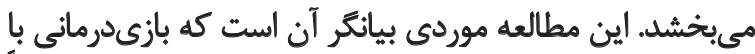

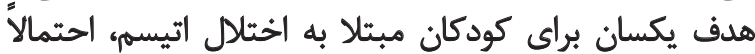

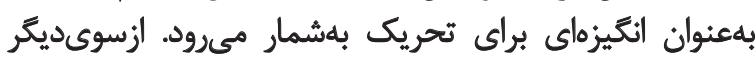

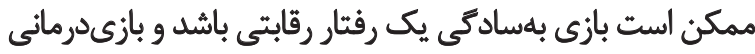

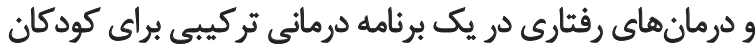

مبتلا به اختلال اتيسم، بهشكل مكمل استفاده شود [بسانس]

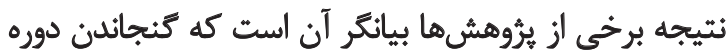

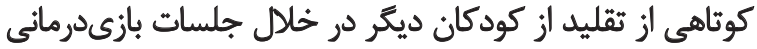

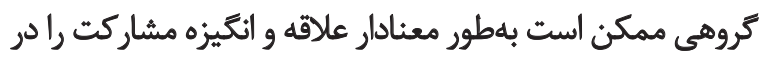

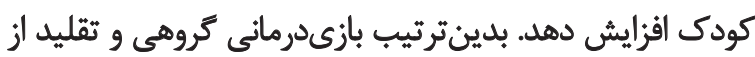

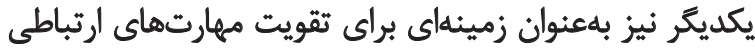

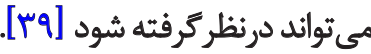
ويرّكى ذاتى كودكان مبتلا به اختلال اتيسم (شامل نقص در ارتباط اوليه و تعامل اجتماعى و يادكيرى)، ممكن است بر تعامل

42. Gillian and Konstantareas

43. Thorp, Stahmer and Schreibman

44. Posture

45. Josefi and Ryan 
فقدان علاقه به فعاليثها نيز تا حدود زيادى كاهش يافته بود. بانظر ميرسد ثابتبودن بازىها و كودكان شركت كنينده در بردي

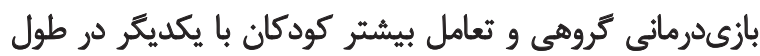

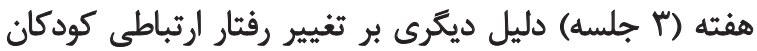

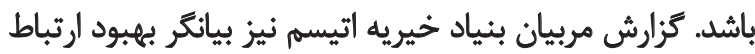

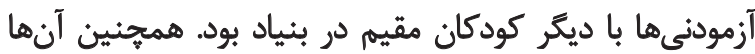

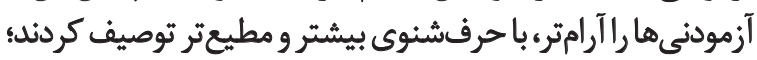

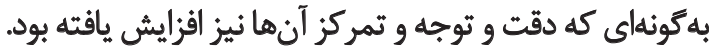

يافتههاى كيفى و تزارش والدين كودكان مبتلا به اختلال

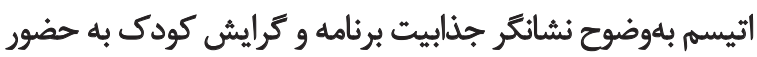

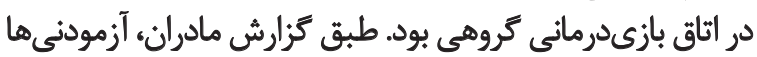

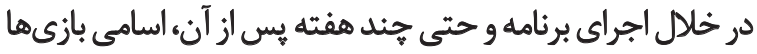

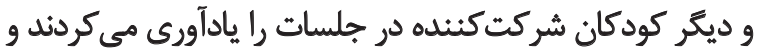

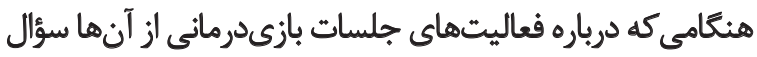

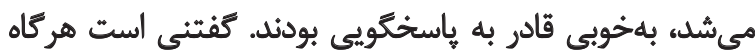

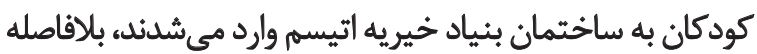

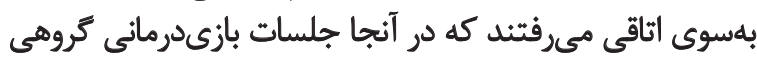

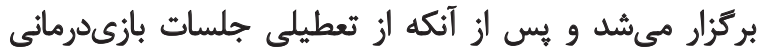

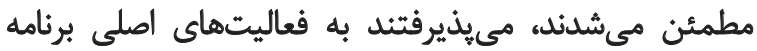
متداول (شامل كفتتاردرماني و كاردرماني) بيردازئند

درمجموع مى توان نتيجه كرفت كودى مبتلا به اختلال اتيسم

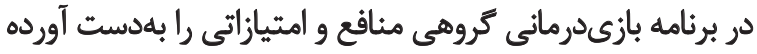

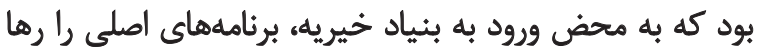

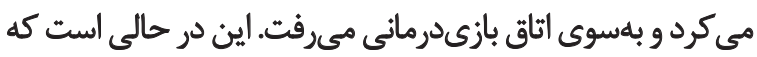

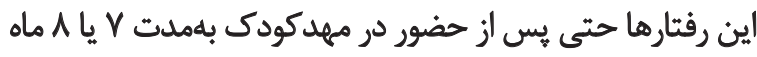

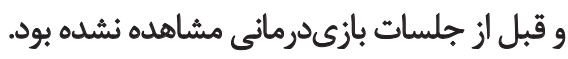

\section{نتيجليَيرى}

باتوجهبه مؤثربودن بازى درمانى كروهى بر بهبود ارتباط كودكان

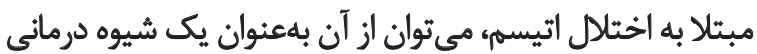

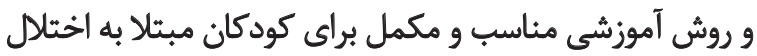

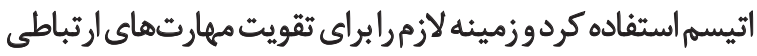

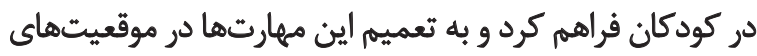

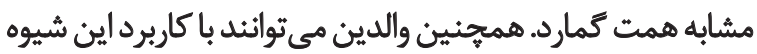

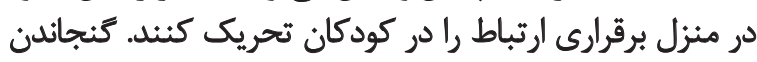

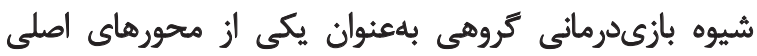

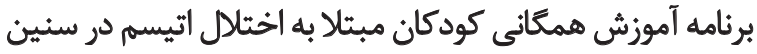

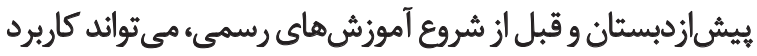

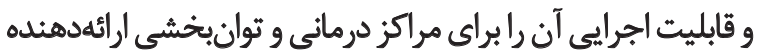

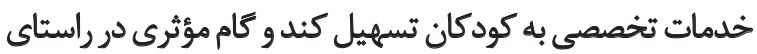
آموزش مهارتهائ ارتباطى بردارد.

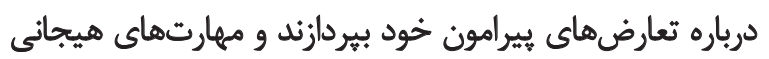

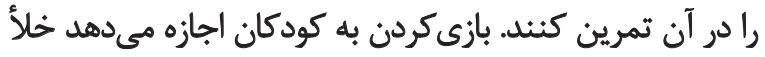

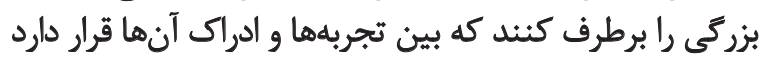

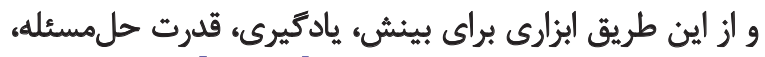

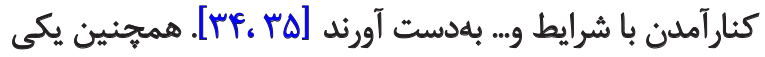

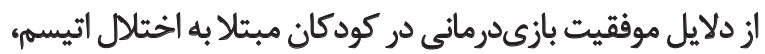

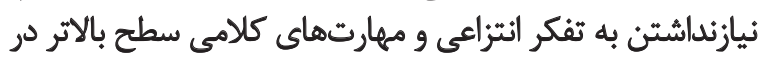

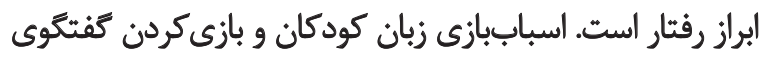

آنها محسوب ميشار استود [عبازيان.

بازى اغلب اجتماعمحور است و بهواسطه بازى تجارب عاطفى و

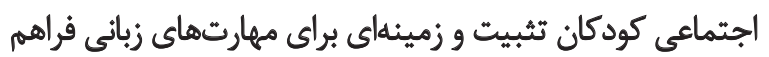

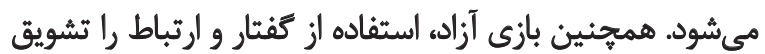

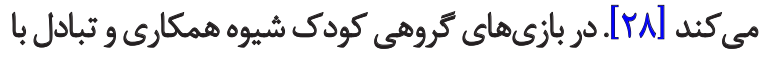

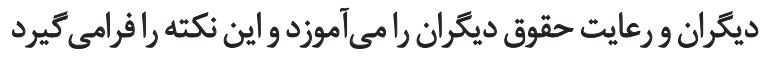

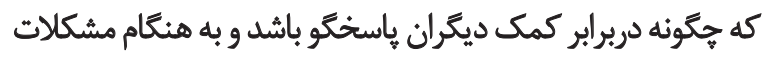

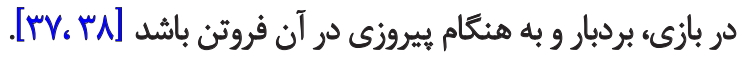

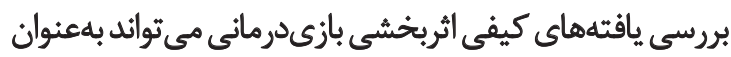

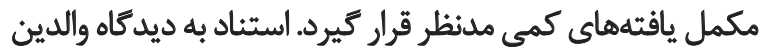

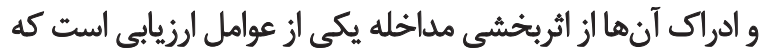

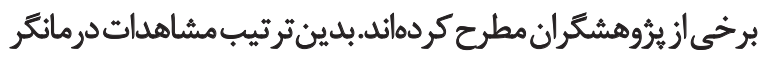

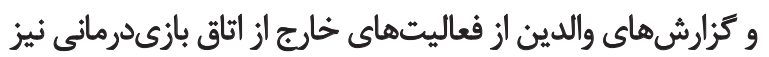

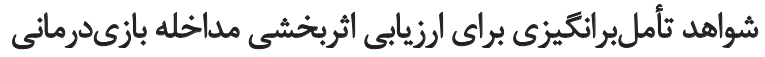

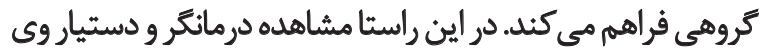

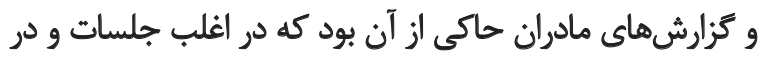

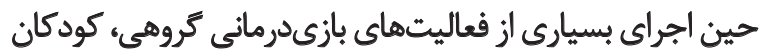

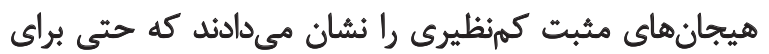
مادران و مربيان نيز دورازانتظار بود.

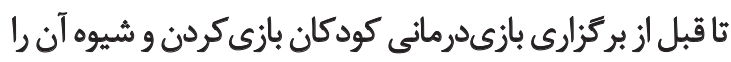

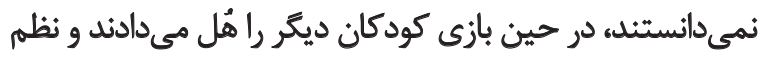

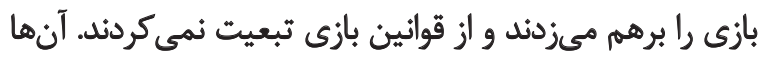

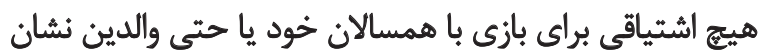

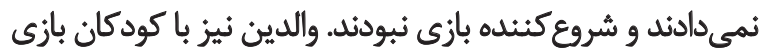

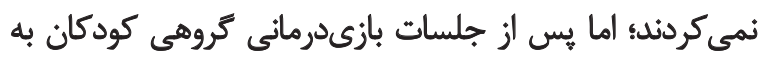

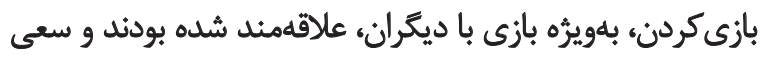

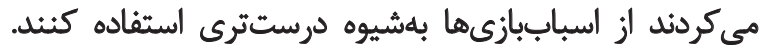

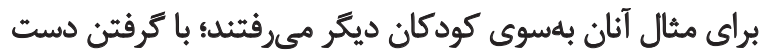

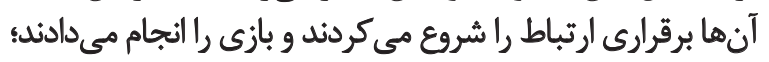

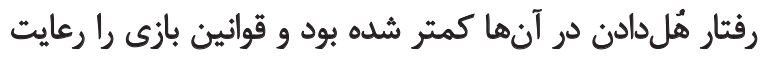

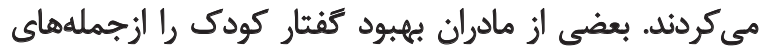

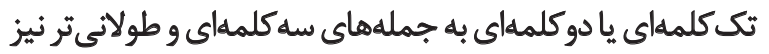

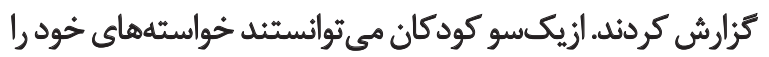

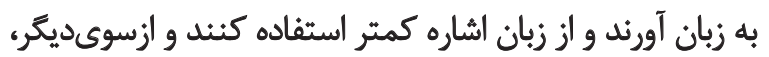

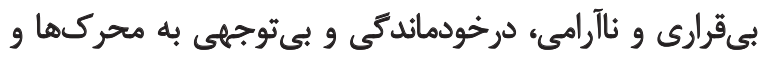




\section{References}

[1] Fouladgar M, Bahramipoor M, Ansari Shahidi M. [Autism (Persian)]. 1st Ed. Isfahan: Jahad-e Daneshgahi; 2009.

[2] Lord C, McGee J. Educating children with autism. Washington D.C.: National Academy Press; 2001.

[3] American Psychiatry Association. Diagnostic and statistical manual of mental disorders [MR. Nykkhoo \& H. Avadysyans Persian trans]. Tehran: Danzheh Publishing Co; 2002.

[4] Centers for Disease Control and Prevention. [Prevalence of autism spectrum disorders; Autism and Developmental Disabilities Monitoring Network, United States (Internet)]. 2012. [Cited 2012 March 30]. Available from: https://www.cdc.gov/mmwr/preview/mmwrhtml/ss6103a1.htm

[5] Center for Disease Control and Prevention. Autism spectrum disorder: from numbers to know-how (Internet)]. 2014. [Cited 2014 April 22]. Available from: http://www.cdc.gov/cdcgrandrounds/ archives/2014/april2014.htm

[6] World Health Organization. Questions and answers about autism spectrum disorders (ASD) (Internet)]. 2016. [Cited 2016 March 15]. Available from: www.who.int/features/qa/85/en/

[7] Dawson G, Osterling J. Early intervention in autism: effectiveness and common elements of current approaches. In: Guralnick MJ, editor. The Effectiveness of Early Intervention. Baltimore: Paul H Brookes Pub; 1997, 9. 214-227.

[8] Tazkerat Tavassoli SH, Banijamali SHS. [Logotherapy's effects on social interaction, communication and stereotype behavior of children with Asperger Syndrome and high functioning autism (Persian)]. Journal of Exceptional Children. 2011; 1(2-3):25-48.

[9] Landa R. Early communication development and intervention for children with autism. Mental Retardation and Developmental Disabilities Research Reviews. 2007; 13(1):16-25. doi: 10.1002/ mrdd.20134.

[10] Owens G, Granader Y, Humphrey A, \& Baron-Cohen S. Logo therapy and the social use of language programme: an evaluation of two social skills interventions for children with high functioning autism and Asperger Syndrome. Journal of Autism and Developmental Disorders. 38(10):1944-57. doi: 10.1007/s10803008-0590-6. 2008.

[11] Gray DE. Ten years on: a longitudinal study of families of children with autism. Journal of Intellectual Disability Research. 2002; 27(3):215-22. doi: 10.1080/1366825021000008639

[12] Ingersoll B, Schreibman L. Teaching reciprocal imitation skills to young children with autism using a naturalistic behavioral approach: effects on language pretend play, and joint attention. Journal of Autism and Developmental Disorders. 2006; 36(4):487505. doi: 10.1007/s10803-006-0089-y.

[13] Golabi P, Alipour A, Zandi B. [The effect of ABA therapeutic intervention on children with autism disorder (Persian)]. Journal of Research in Exceptional Children. 2005; 15(1):33-54.

[14] Wall K. Education and care of adolescents and adults with autism: Guide for professionals and caregivers [A. Jahanian $\mathrm{Na}$ jafabadi, H. Aflakian (Persian trans)]. Tehran: Danzheh Publishing Co; 2009.

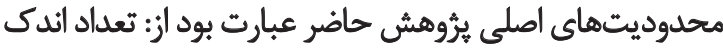

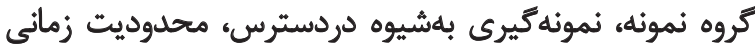

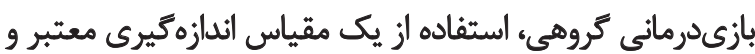

$$
\begin{aligned}
& \text { يايا در حوزه ارتباط كودكان مبتلا به اختالال اتيسه. } \\
& \text { Aslein }
\end{aligned}
$$

$$
\begin{aligned}
& \text { علاوهبر تهيه و استفاده از ديكر ابزارهاى معتبر در حيطه ارتباط }
\end{aligned}
$$

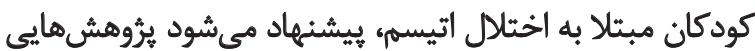

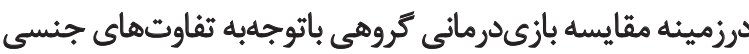

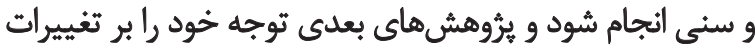

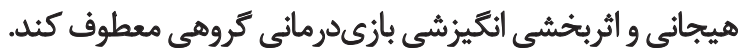

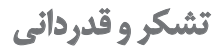

$$
\begin{aligned}
& \text { مقاله حاضر بركرفته از ياياننامه كارشناسى ارشد خانم فاطمه }
\end{aligned}
$$

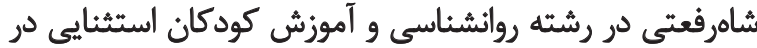

$$
\begin{aligned}
& \text { دانشكاه علوم بهزيستى و توانبخشى تهران است. }
\end{aligned}
$$


[15] Matson JL. Clinical assessment intervention for autism spectrum disorders. Washington: Elsevier Pub; 2008.

[16] Luiselli JK, Russo DC, Christian WP, Wilcyznski SM. Effective practices for children with autism: educational and behavior support interventions that work. Oxford: Oxford University Press; 2008.

[17] Landreth L, Ray DE, Bratton S. Play therapy in elementary schools. Psychology in the Schools, 2009; 46(3):281-289. doi: 10.1002/pits.20374

[18] Parker N, O'Brien P. Play therapy-reaching the child with autism. International Journal of Special Education, 2011; 26(1):80-87. doi: 10.1111/j.1469-7610.1985.tb01956.x

[19] Lu L, Petersen F, Lacroix L, Rousseau C. Stimulating creative play in children with autism through sand play. The Arts in Psychotherapy, 2010; 37(1):56-64. doi: 10.1016/j.aip.2009.09.003

[20] Davis NO, Carter AS. Parenting stress in mothers and fathers of toddlers with autism spectrum disorders: associations with child characteristics. Journal of Autism and Developmental Disorders. 2008; 38(7):1278-91. doi: 10.1007/s10803-007-0512-z.

[21] Ray DE. Supervision of basic and advanced skills in play therapy. Journal of Professional Counselling, Practice, Theory, \& Research. 2004; 32(2):28-41. doi: 10.1177/002234097703100209

[22] Jones KD. Group play therapy with sexually abused preschool children: group behaviors and interventions. Journal for Specialists in Group Work. 2002; 27(4):377-89. doi: 10.1080/714860200

[23] Ahmadi SJ, Safari T, Hemmatian M, \& Khalili Z. [Study psychometric indices of Autism Diagnostic Test GARS (Persian)]. Journal of Cognitive and Behavioral Sciences, 2011; 1(1):87-104.

[24] O'Conner K. The play therapy primer. New York: Wiley \& Sons; 2000.

[25] Jennings S. Introduction to developmental play therapy playing and health. London: Jessica Kingsley Publishers. 1999.

[26] Maddox LL. Effects of systematic social skills training on the social-communication behaviors of young children with autism during play activities. $[\mathrm{PhD}$ thesis] Nebraska: University of Nebraska; 2010.

[27] Kroeger KA, Schultz JR, Newsom C. A comparison of two group-delivered social skills programs for young children with autism. Journal of Autism and Developmental Disorders. 2007; 37(5):808-17. doi: 10.1007/s10803-006-0207-x.

[28] Gillian C, Stanley G, Konstantareas MM. Symbolic play in children with autism spectrum disorder. Journal of Autism and Developmental Disorders. 2006; 37(7):1215-23. doi: 10.1007/ s10803-006-0263-2.

[29] Thorp DM, Stahmer AC, \& Schreibman L. Effects of sociodramatic play training on children with autism, Journal of Autism and Developmental Disorders. 1995; 25(3):265-282. doi: 10.1007/bf02179288

[30] Akhavan B, Pishyareh E, Raboubi H. [Effect of play therapy on enhancing communication skills in autistic children (Persian)].Paper presented at: The 5th International Conference on Child and Adolescent Psychiatry; 2012 October 8-11; Tehran University of Medical Sciences, Tehran.
[31] Moghim Islam P, Pourmohamadreza-Tajrishi M, Haghgoo H. [The impact of reciprocal immitation training on social skills of children with autism (Persian)]. Journal of Rehabilitation. 2013; 61(6):59-67.

[32] Asghari Nekah SM, Afrooz GA, Bazargan A, Shokoohi Yekta M. [The effect of puppet play therapy intervention on communicative skills of autistic children (Persian)]. Journal of Fundamentals of Mental Health. 2011; 13(1):42-57.

[33] Josefi O Ryan V. Non-directive play therapy for young children with autism: a case study. Clinical Child Psychology and Psychiatry. 2004; 9(4):533-51. doi: 10.1177/1359104504046158

[34] Rajabi Shamami B, Pourmohamadreza-Tajrishi M, Haghgoo H, Vosougi A, Biglarian A. [The effect of pivotal response training on behavioral problems of 4-6 years old children with autism (Persian)]. Journal of Rehabilitation. 2014; 14(3):50-58.

[35] Bratton S, Ray D, Rhine T, Jones L. The efficacy of play therapy with children: a meta-analytic review of treatment outcomes. Professional Psychology, Research and Practice. 2005; 36(4):376-390. doi: 10.1037/0735-7028.36.4.376.

[36] Sohrabi Shegefti N. [Various methods of play therapy and its application on treatment of behavioral and emotional disorders in children (Persian)]. Journal of Psychological Methods and Models. 2011; 1(4):45-63.

[37] Mohammed Esmaeel A. [Play therapy: Theory, Methods and Clinical Applications (Persian)]. 1st Ed. Tehran: DanzHeh. 2003.

[38] Kdasn HJ, Schaefer CY. Selective play therapy methods [S. Saberi, P. Vakili (Persian trans)]. Tehran: Agah Publishing Co; 2007.

[39] Heimann M, Laberg KE, Nordoen B. Imitative interactin increases social interest and elicited immitation in non-verbal children with autism, Infant and child Development. 2006; 15(3):297309. doi: $10.1002 /$ icd. 463

[40] Paul R. Interventions to improve communication in autism. Child and Adolescent Psychiatric Clinics of North America. 2008; 17(4):835-56. doi: 10.1016/j.chc.2008.06.011

[41] Lawver T, Blankenship K. Play therapy: a case-based example of a nondirective approach Psychiatry (Edgmont). 2008; 5(10):2428.

[42] Jekan M, Hoseini SA, Mohammadi MR, Salehi M. [The effects of ball skills training on adaptive behaviors of children with high functioning autism (Persian)]. Journal of Rehabilitation. 2013; 13(5):136-144.

[43] Olson MH, Hrgnhan BR. Introduction to theories of learning [AK. Seif Persian trans]. Tehran: Dowran; 2011.

[44] Vameghi R, Hemmati S, Sajedi F, Gharib M, PourmohamadrezaTajrishi M, Teymori R. The effect of neurofeedback on brain waves in children with autism spectrum disorders. Iranian Rehabilitation Journal. 2016; 14(2): In Press.

[45] Esbati M, Roberts J M. Autism treatment and family support models review. Iranian Rehabilitation Journal. 2009; 7(1):44-49. 